\title{
Demographic Study of Gujjars of Delhi: V. Maternal and Child Health Care Practices
}

\author{
Shweta Dabral and S.L. Malik \\ Department of Anthropology, University of Delhi, Delhi 110 007, India
}

KEYWORDS Antenatal Care. Delivery Care. Child Immunization. Child Morbidity. Breastfeeding.

\begin{abstract}
Mother and child constitute the special risk group and their health is considered of priority interest. The risk in case of mother is connected with child bearing while in the case of infant and children are connected with growth, development and survival. Keeping this in mind a demographic study was conducted among Gujjar women of Delhi. The data for present study was collected by interviewing ever-married Gujjar women aged 15-49 years from a sample of 221 households. Majority of Gujjar mothers received antenatal check-ups, though institutional deliveries are less common. The median number of check-ups for those who received at least one check-up is 3 visits. The median timing of the first antenatal check-up among Gujjar women of Delhi is 4 months i.e., during second trimester of pregnancy. The coverage of other two interventions, namely two tetanus toxoid injections and full course of iron and folic acid supplementation is also incomplete. Higher educated mothers have more likelihood for antenatal care and institutional deliveries. Majority of the deliveries in last four years had no complications. Immunization coverage among Gujjar children is incomplete. Proportion of 'fully' vaccinated children is low. Vitamin A supplementation below 5 years of age is not only incomplete, but also irregular. Diarrhoea is the most frequent cause of child morbidity among Gujjars. Treatment of the three childhood ailments under study is fairly high. The likelihood of using ORS increases with increase in the level of education of the mother. Breastfeeding is universal among Gujjars; however supplementation begins relatively early. Slightly more than half of the children begin breastfeeding within 24 hours of birth. Majority of children among Gujjars have stopped breastfeeding by 24-29 months of age.
\end{abstract}

\section{INTRODUCTION}

Traditionally, in most parts of India the status of women has been considered lower than their man-folk. Women are often discouraged, prevented and occasionally suppressed from going against the wishes of their elderly males of the household and society. This may be one of the reasons that not much attention is given to maternal care during pregnancy and postnatal stages in rural areas, particularly, if there is no complication. Maternal mortality in rural India is as high as two percent of total female deaths (RGI, 1997). Deplorably, majority of these deaths are preventable. In the health services, conceptualization and assessment of the health and the quality of life have received increased attention. Further, the health problems of women and children have been identified as priority interest. These considerations have led to the formulation of special health services for mothers and children all over the world, including India. Efforts have been made for maternal and child services since the beginning of planned

Address Correspondence to: Dr. S. L. Malik, Professor, Department of Anthropology, University of Delhi, Delhi 110 007, India

E-mail: slmalik@rediffmail.com development in India. Various programmes and policies have come up, from time to time in India, with a view of improving mother and child health. Besides, different goals were set to assess the efficiency of these health policies. Moreover, there has been a considerable decline in IMR and MMR during past few decades, due to positive strategies of the government and imp-rovement in education and attitude of women. However, much remains to be done to improve health care for women and children both in qualitative and quantitative terms. Improvements in female health status are critically dependent on a number of nonhealth development compo-nents such as education, opportunities for employment and decision-making.

Due to unequal sharing of responsibility of conception and contraception, women bear their consequences, which often lead to mortality. Maternal mortality constitute for good proportion of death among women in their prime years. Younger mothers are not physiologically completely prepared for the process of reproduction (Montagu, 1963). A variety of congenital malformation of the circulatory and nervous system is more prevalent among the children of the older mother (NewCombe, 1964). Inadequate care of mothers and inappropriate management of complication during pregnancy and delivery, poor 
hygiene during delivery, age of mother at time of birth, parity, previous birth interval, survival status of previous child, are factors that lead to maternal death. Health of the mother and the child is affected by numerous socio-economic factors (Wyon and Gordon, 1971), such as lower women's status and gender bias, lower female education, lack of access to health services and economic dependency.

Antenatal care is an important aspect of maternal health. Ideally, for normal cases antenatal care visits after confirmation of pregnancy should be scheduled at intervals of four weeks throughout the first seven months, thereafter every two weeks until the last month and weekly thereafter (MacDonald and Pritchard, 1980). However, a minimum of three antenatal visits are recommended, first during fifth month or as soon as the pregnancy is known, second during eighth month and last during ninth months of the pregnancy (MHFW, 1997; Park, 1997). Women, especially living in remote areas hardly feel the need of visiting (PHC during pregnancy unless there is a complication (Mano-cha et al., 1992). The type of care received at child birth is often critical for the health and survival of both the infant and the mother. Family support at the time of birth is also important. In most of the rural and tribal societies traditional health behaviour not only dominates over the modern ones but also very often hinders the acceptance of the latter (Guha, 1990; Kar, 1993). A significant proportion of neonatal deaths are attributed to poor birth practices (UNICEF, 1990). Improved nutrition coupled with improved health care in pregnancy, substantially improves birth weights and reduces perinatal mortality (Ramachandran, 1992).

For the growth and immunity of the baby, breastfeeding is essential (Reddy, 1995; Park, 1997). The duration of breastfeeding is determined by the factors, like survival of the baby, age of the mother, parity, education of the mother, gender of the child (Jain and Bongaarts, 1981; Mott, 1984; Smith, 1985; Ahmed and Alam, 1996). Duration of breastfeeding is more in the developing countries, rural areas, and less educated women (Mott, 1984; Mohiuddin, 1986; Joesoef et al., 1988). In societies where breastfeeding is nearly universal, prolonged and of higher intensity, it is a major determinant of prolonged postpartum amenorrhoea, birth interval and resumption of next menses (Singh and Negi,
1985; Srinivasan et al., 1989; Singh et al., 1994; Babu, 1996; Singh et al., 1999). Maternal and child health is affected by a whole range of socioeconomic determinants, such as status of women, lower level of female education, economic dependency, lack of access to health services and gender bias (Wyon and Gordon, 1971). Improved nutrition, coupled with improved health care in pregnancy, substantially improves birth weights and reduces perinatal mortality (Ramachandran, 1992). Good health of the child is related to maternal education as well as higher income as they influences the use of preventive health service like immunization (Streatfield et al., 1990; Otta, 1992).

In India, Maternal and Child Health (MCH) programme is now incorporated into Reproductive and Child Health programme that was launched in 1997. The focal elements with regards to $\mathrm{MCH}$ includes provision of antenatal care, encouragement of institutional deliveries and home deliveries assisted by trained health personnel, and provision of postnatal care. The programme also includes Oral Re-hydration Therapy (ORT) programme, and Universal Immunization programme. 'Child Survival and Safe Motherhood' constitute one of the most important programmes run by the Government of India. Proper care during the antenatal period and during delivery is crucial for good health of both the mother and the child. In India, the major causes of infant and child mortality are low birth weight, diarrhoeal diseases, acute respiratory infections and inadequate maternal and newborn care (RGI, 1997; NIHFW report 1999-2000). $\mathrm{MCH}$ services in India are provided primarily through a network of Primary Health Centres and Sub-Centres in rural areas and government hospitals and family welfare centres in urban areas. Besides this, these services are also available through private hospitals, maternity homes and clinics as well as hospitals operated by non-governmental organizations. The National Population Policy (2000) has set the goals that pertain to safe motherhood and empowering women for improved health and nutrition.

The present paper highlights prevailing practices pertinent to maternal health care namely antenatal care and delivery care, besides, current child care practices namely child immu-nization, child morbidity and treatment pattern and infant breastfeeding practice among Hindu Gujjars of Delhi. 


\section{MATERIAL AND METHODS}

The present study was conducted among Hindu Gujjars residing in Delhi. Five Gujjar predominated villages selected at random, were visited during different months of the year 2002. In the present study, the data was collected for the last birth that took place within four years prior to study. The information on children morbidity pattern was collected for two weeks period prior to study. Mothers aged 15-49 years were interviewed using a structured interview schedule from a sample of 221 households. Not more than one mother in the reproductive age group was selected from each household. Incase, of more than one mother per household, the eldest woman was selected (For details see Dabral and Malik, 2000a). Data collected was statistically treated, using descriptive statistics.

\section{RESULTS AND DISCUSSION}

Antenatal Care: Antenatal care refers to pregnancy-related health care provided by a doctor or a health worker in a medical facility or at home or both. It is a crucial facet of maternal health. It contributes significantly in reduction of maternal morbidity and mortality. Under antenatal care, pregnancy complication signs, diet during pregnancy, delivery and post natal care, and related issues are monitored. Ideally, for normal pregnancies, once the pregnancy is confirmed, women should go for antenatal check-ups at a regular interval of four weeks during first seven months, then every two weeks until last month and weekly thereafter (MacDonald and Pritchard, 1980). However, in India, a minimum of three antenatal check-ups have been recommended (MHFW, 1997; Park, 1997). As per MCH programmes, a pregnant woman should receive two doses of tetanus toxoid vaccine, hundred tablets of iron and folic acid or syrup, and at least three antenatal check-ups. Improved nutrition coupled with proper health care during pregnancy, can substantially increase birth weights (about one-third of the babies in India are of low birth weight). Among Gujjars, three-fourth of the mothers have received antenatal check-ups (Table 1). Of all those who received ANC, cent percent have received antenatal check-ups outside home in health institutions (no one received it at home from a health worker) indicating that health institutions are accessible to Gujjar women in the areas of the present study. For less than threefourth of the mothers who did not have any antenatal check-up, mothers reported that antenatal check-ups are not necessary. Some studies have revealed that rural women hardly felt the need of visiting a Primary Health Centre during pregnancy unless there is a complication (Manocha et al., 1992).

For one in every eight women, check-ups are too costly. For each less than ten percent of the births, mothers said that their families did not allow them to get antenatal check-ups or they did not have time to go for antenatal check-ups (Table 1). This indicates that there are still substantial number of women among Gujjars who need to be educated about the availability and benefits

Table 1: Percentage of live births (during the four-year period prior to the study), by whether the mother received antenatal check-ups and if not, then reasons for not receiving antenatal check-ups

\begin{tabular}{lcc}
\hline Antenatal check-ups & Number & Percent \\
\hline Received ANC & & \\
Yes, received & 165 & 74.7 \\
No ANC & 56 & 25.3 \\
\hline Total & 221 & 100.0 \\
\hline Reasons for not Receiving Any ANC & \\
Not necessary & 40 & 71.5 \\
No time to go & 5 & 8.9 \\
Not permitted & 4 & 7.1 \\
$\quad$ by family & & 12.5 \\
Cost too much & 7 & 100.0 \\
\hline Total & 56 & \\
\hline
\end{tabular}

Table 2: Percentage of live births (during the four-year period prior to the study), by number of antenatal checkup (ANC) visits and, by the stage of pregnancy at the time of first visit

\begin{tabular}{lcr}
\hline $\begin{array}{l}\text { ANC visits/ } \\
\text { months pregnant }\end{array}$ & Number & \\
\hline Number of ANC visits & & \\
1-2 visits & 37 & 22.4 \\
3 visits & 68 & 41.2 \\
4 or more visits & 60 & 36.4 \\
Total & 165 & 100.0 \\
Median & 3 & \\
Months Pregnant at the Time of First ANC Visits & \\
First trimester & 57 & 34.5 \\
Second trimester & 98 & 59.4 \\
Third trimester & 10 & 6.1 \\
\hline Total & 165 & 100.0 \\
\hline
\end{tabular}

Median 4 months (Second trimester) 
of antenatal check-ups so as to overcome the traditional beliefs that prevents mothers from seeking antenatal care. Among Gujjars, less than four-fifth of the mothers received at least three antenatal check-ups (Table 2). The median number of check-ups is 3 visits. Among mothers who received antenatal care, slightly over onethird are those who have received first antenatal check-up in the first trimester of pregnancy (Table 2). While three-fifth are those, who have received first antenatal check-up in the second trimester. The median timing of the first antenatal checkup among Gujjar women of Delhi is 4 months i.e., during second trimester of pregnancy. This is in accordance to the guidelines given by the Ministry of Health and Family Welfare, GOI i.e., there should be at least three antenatal care visits by the women and that first check-up should take place at least during the second trimester of pregnancy (MHFW, 1997).

Neonatal tetanus is caused by infection of the newborn, usually at the umbilical stump, caused by tetanus organisms. It is most common among children who are delivered in unhygienic environment and using non-sterilized instruments. In India, it is a prominent cause of infant death. Neonatal Tetanus, however, is a preventable disease. Tetanus toxoid coverage among Gujjar women is incomplete (Table 3). Iron deficiency anaemia is the most common micronutrient deficiency. It is one of the major threats to safe motherhood and to the survival and health of the infant as it contributes to low birth weight and lower resistance to infection, etc. Eleven percent of the mothers who have received iron and folic acid supplements did not consume them while another two-third of the mothers have consumed all what they had received (Table 3). This reflects that there is a need to make mothers aware of the benefit and necessity of iron and folic acid supplements for their betterment and the health of the baby.

Delivery Care: A significant proportion of neo-natal deaths are attributed to the poor birth practices (UNICEF, 1990). In India, deliveries under proper hygienic conditions and under the supervision of trained health professionals is an important thrust of the Reproductive and Child Health programme. Majority of births among Gujjars have took place in women's own home while over one-third have took place in health facilities (Table 4). Out of the births in health facilities, only small proportion have took place
Table 3: Percentage of live births (during the four year period prior to the study), by whether the mother received tetanus toxoid injections, if yes, then number of injections and whether iron/ folic acid syrup/ tablets were given to them during pregnancy

\begin{tabular}{lcc}
\hline $\begin{array}{l}\text { Vaccinations } \\
\text { and tablets }\end{array}$ & Number & Percent \\
\hline $\begin{array}{l}\text { Immunized with Tetanus } \\
\text { Yes }\end{array}$ & 176 & \\
No & 45 & 79.6 \\
\hline Total & 221 & 20.4 \\
\hline If received, then Number of Injections & 100.0 \\
One & 14 & \\
Two or more & 162 & 92.0 \\
\hline Total & 176 & 100.0 \\
\hline Received Iron/ Folic Acid Syrup/ Tablets & \\
Yes & 146 & 66.1 \\
Yes, but not taken & 24 & 10.9 \\
No & 51 & 23.1 \\
\hline Total & 221 & 100.0 \\
\hline
\end{tabular}

in public health facilities. Institutional deliveries are more common for births to mother aged 1519 years than for mothers aged $20+$. They are also more common for first births (more than three-fifth) than for later births. The likelihood of institutional delivery increases with mother's education among Gujjars indicating that awareness about the benefits of professional medical care during pregnancy and delivery is more among the women with higher education (Table 4).

Similarly, the percentage of institutional deliveries also increases with the number of antenatal check-ups that a mother had. This reflects the availability of services for both antenatal care and delivery in the same settings and possibly antenatal care provider advised them to deliver in a health facility. Over two-fifth of the births in the last four years are attended by traditional birth attendants (Table 5). Less than three-fifth are attended by a health professional. A doctor has attended twice as frequent births as attended by a nurse/midwife. The proportion of births attended by a doctor varies from over half for mothers aged 14-19 years to two-fifth for mothers aged $35+$. The proportion attended by a doctor decreases with increases in parity while it increases with mother's level of education. Thus, education plays an important role in the awareness of women about health services and acceptability of such services by influencing their attitude. Only 
Table 4: Percent distribution of live births (during the four-year period prior to the study), by place of delivery and selected characteristics

\begin{tabular}{|c|c|c|c|c|c|}
\hline Characteristic & $\begin{array}{c}\text { Public medical } \\
\text { institutions }\end{array}$ & $\begin{array}{c}\text { Private medical } \\
\text { institutions }\end{array}$ & At home & Total percent & $\begin{array}{l}\text { Number of } \\
\text { live births }\end{array}$ \\
\hline \multicolumn{6}{|l|}{ Mother's Age at Birth } \\
\hline $15-19$ & 5.6 & 50.0 & 44.4 & 100.0 & 18 \\
\hline $20-34$ & 3.5 & 31.3 & 65.2 & 100.0 & 198 \\
\hline $35+$ & - & 40.0 & 60.0 & 100.0 & 5 \\
\hline \multicolumn{6}{|l|}{ Birth Order } \\
\hline 1 & 10.6 & 53.2 & 36.2 & 100.0 & 47 \\
\hline $2-3$ & 1.7 & 31.7 & 66.7 & 100.0 & 120 \\
\hline $4-5$ & 2.3 & 16.3 & 81.4 & 100.0 & 43 \\
\hline $6+$ & - & 27.3 & 72.7 & 100.0 & 11 \\
\hline \multicolumn{6}{|l|}{ Mother's Education } \\
\hline Illiterate & 1.8 & 23.6 & 74.5 & 100.0 & 55 \\
\hline$<$ Primary school & - & 16.7 & 83.3 & 100.0 & 12 \\
\hline Primary school & 4.0 & 28.0 & 68.0 & 100.0 & 50 \\
\hline Middle school & 1.8 & 36.4 & 61.8 & 100.0 & 55 \\
\hline High school & 6.7 & 40.0 & 53.3 & 100.0 & 30 \\
\hline Higher secondary & 8.3 & 66.7 & 25.0 & 100.0 & 12 \\
\hline Graduation & 16.7 & 50.0 & 33.3 & 100.0 & 6 \\
\hline Post graduation & - & 100.0 & - & 100.0 & 1 \\
\hline \multicolumn{6}{|l|}{ Antenatal Care Visits } \\
\hline None & 1.8 & - & 98.2 & 100.0 & 56 \\
\hline $1-2$ visits & 5.4 & 10.8 & 83.8 & 100.0 & 37 \\
\hline 3 visits & 2.9 & 41.2 & 55.9 & 100.0 & 68 \\
\hline $4+$ visits & 5.0 & 68.3 & 26.7 & 100.0 & 60 \\
\hline Number & 8 & 73 & 140 & - & 221 \\
\hline Percent & 3.6 & 33.0 & 63.3 & 100.0 & - \\
\hline
\end{tabular}

Table 5: Percent distribution of live births (during the four-year period prior to the study), by type of assistance during delivery and selected characteristics

\begin{tabular}{|c|c|c|c|c|c|c|}
\hline Characteristic & Doctor & $\begin{array}{l}\text { Nursel } \\
\text { Midwife }\end{array}$ & $\begin{array}{c}\text { Traditional } \\
\text { birth attendant }\end{array}$ & Relative & $\begin{array}{c}\text { Total } \\
\text { percent }\end{array}$ & $\begin{array}{l}\text { Number of } \\
\text { live births }\end{array}$ \\
\hline \multicolumn{7}{|l|}{ Mother's Age at Birth } \\
\hline $15-19$ & 55.6 & - & 44.4 & - & 100.0 & 18 \\
\hline $20-34$ & 36.9 & 21.2 & 41.4 & 0.5 & 100.0 & 198 \\
\hline $35+$ & 40.0 & - & 60.0 & - & 100.0 & 5 \\
\hline \multicolumn{7}{|l|}{ Birth Order } \\
\hline 1 & 66.0 & 8.5 & 25.5 & - & 100.0 & 47 \\
\hline $2-3$ & 34.2 & 19.2 & 45.8 & 0.8 & 100.0 & 120 \\
\hline $4-5$ & 23.3 & 30.2 & 46.5 & - & 100.0 & 43 \\
\hline $6+$ & 27.3 & 18.2 & 54.5 & - & 100.0 & 11 \\
\hline \multicolumn{7}{|l|}{ Mother's Education } \\
\hline Illiterate & 29.1 & 20.0 & 50.9 & - & 100.0 & 55 \\
\hline$<$ Primary school & 16.7 & 25.0 & 58.3 & - & 100.0 & 12 \\
\hline Primary school & 34.0 & 18.0 & 48.0 & - & 100.0 & 50 \\
\hline Middle school & 40.0 & 23.6 & 36.4 & - & 100.0 & 55 \\
\hline High school & 46.7 & 16.7 & 33.3 & 3.3 & 100.0 & 30 \\
\hline Higher secondary & 75.0 & 8.3 & 16.7 & - & 100.0 & 12 \\
\hline Graduation & 66.7 & - & 33.3 & - & 100.0 & 6 \\
\hline Post graduation & 100.0 & - & - & - & 100.0 & 1 \\
\hline \multicolumn{7}{|l|}{ Antenatal Care Visits } \\
\hline None & 1.8 & 21.4 & 76.8 & - & 100.0 & 56 \\
\hline $1-2$ visits & 21.6 & 18.9 & 56.8 & 2.7 & 100.0 & 37 \\
\hline 3 visits & 45.6 & 20.6 & 33.8 & - & 100.0 & 68 \\
\hline $4+$ visits & 75.0 & 15.0 & 10.0 & - & 100.0 & 60 \\
\hline \multicolumn{7}{|l|}{ Place of Delivery } \\
\hline Public health institution & 100.0 & - & - & - & 100.0 & 8 \\
\hline Private health institution & 100.0 & - & - & - & 100.0 & 73 \\
\hline At home & 2.9 & 30.0 & 66.4 & 0.7 & 100.0 & 140 \\
\hline Total Number & 85 & 42 & 93 & 1 & - & 221 \\
\hline Percent & 38.5 & 19.0 & 42.1 & 0.5 & 100.0 & - \\
\hline
\end{tabular}


negligible proportion of the births to mothers who did not have any antenatal check-up, are attended by doctors as compared to three-fourth of births to mothers who have four or more antenatal check-ups (Table 5).

Over three-fourth of births to mothers who did not have any antenatal check-ups are attended by traditional birth attendants. Cent percent of the births in public and private health institutions are delivered by a doctor, while two-third of the births in mother's own home, are attended by traditional birth attendants (Table 5). As reported by mothers, majority of the deliveries in last four years have no compli-cations while less than ten percent of the children are delivered by caesarian section (Table 6). Negligible percentages of live births are reported as premature. Low birth weight babies are at higher risk of dying than do normal birth weight babies. More than half of the babies are not weighed at birth, which is expected given that majority of the deliveries have took place at home. Few percent did not remember the birth weight. Eight percent of the babies, whose birth weight was reported, weighed less than $2.5 \mathrm{~kg}$ i.e., are low birth weight.

Child Immunization: The status of child immunization among Gujjars is discussed in this section. It is essential that children be fully immunized by the time they complete their first year of life. The standard immunization schedule developed for the immunization programme for children specifies the age at which each vaccine is to be administered, the number of doses to be given and the route of vaccination. Routine

Table 6: Percent distribution of live births (during the four-year period prior to the study), by whether the delivery had complications, whether premature birth, and, by birth weight

\begin{tabular}{lrr}
\hline Delivery & \multicolumn{2}{c}{ Total } \\
\cline { 2 - 3 } characteristics & Number & Percent \\
\hline Complications at Delivery & & \\
$\quad$ No complications & 200 & 90.5 \\
Caesarian section & 17 & 7.7 \\
Prolonged labour & 2 & 0.9 \\
$\quad$ Excessive bleeding & 2 & 0.9 \\
Premature birth & 3 & 1.4 \\
Yes & 218 & 98.6 \\
$\quad$ No & 18 & 8.1 \\
Birth weight & 71 & 32.1 \\
Less than 2.5 kg & 8 & 3.6 \\
2.5 kg or more & 124 & 56.1 \\
Don't know & 221 & 100.0 \\
$\quad$ Not weighed & & \\
\hline Number of births & & \\
\hline
\end{tabular}

vaccinations received by infants and children are usually recorded on a vaccination care that is issued for the child. The Expanded Programme on Immunization was initiated by the Government of India in 1978 with the objective of reducing morbidity, mortality and disabilities from six preventable diseases, namely tuberculosis, diphtheria, pertussis, tetanus, poliomyelitis and measles, by making free vaccination services easily available to all eligible children. In order to accelerate implementation of the immunization scheme, the Government of India, introduced Universal Immunization Programme in 1985-86. Pulse polio immunization cam-paigns began in 1995 as part of the major national effort to eliminate polio.

Among Gujjars, two-third of the children aged 12-23 months are fully vaccinated i.e., who received BCG, measles, and three doses each of DPT and Polio excluding Polio 0 (Table 7). Coverage for each vaccination except Polio 0 is higher than the percentage fully vaccinated. More than four-fifth of children have received $\mathrm{BCG}$, three doses of Polio vaccine and the first and second dose of DPT. The DPT and polio coverage rates are about the same (in case of vaccination card as source of information) because both these vaccines are normally admini-stered simultaneously. Generally, the completion of vaccination series from first to third dose of DPT

Table 7: Distribution of children aged 12-23 months who received vaccines, by source of information

\begin{tabular}{|c|c|c|c|c|c|}
\hline \multirow[t]{2}{*}{$\begin{array}{l}\text { Vacci- } \\
\text { nes* }\end{array}$} & \multirow[t]{2}{*}{$\begin{array}{c}\text { Time } \\
\text { schedule }\end{array}$} & \multicolumn{2}{|c|}{$\begin{array}{l}\text { Source of } \\
\text { information }\end{array}$} & \multicolumn{2}{|c|}{ Total } \\
\hline & & $\begin{array}{c}\text { Vacci- } \\
\text { nation } \\
\text { card }\end{array}$ & $\begin{array}{l}\text { Mo- } \\
\text { ther's } \\
\text { report }\end{array}$ & $\begin{array}{l}\text { Num- } \\
\text { ber }\end{array}$ & $\begin{array}{l}\text { Per- } \\
\text { cent }\end{array}$ \\
\hline olio 0 & Within 48 hrs & th 19 & 5 & 24 & 42.1 \\
\hline $\mathrm{BCG}$ & 0-1 month & 30 & 21 & 51 & 89.5 \\
\hline DPT 1 & $11 / 2$ month & 31 & 20 & 51 & 89.5 \\
\hline Polio 1 & $11 / 2$ month & 31 & 22 & 53 & 93.0 \\
\hline DPT 2 & $21 / 2$ months & 31 & 24 & 55 & 96.5 \\
\hline Polio 2 & $21 / 2$ months & 31 & 20 & 51 & 89.5 \\
\hline DPT 3 & $31 / 2$ months & 26 & 19 & 45 & 78.9 \\
\hline Polio 3 & $31 / 2$ months & 26 & 21 & 47 & 82.5 \\
\hline Measles & $9-12$ months & 29 & 14 & 43 & 75.4 \\
\hline Fully vac & ccinated $^{* *}$ & 26 & 12 & 38 & 66.7 \\
\hline Number & of children & 31 & 26 & 57 & - \\
\hline
\end{tabular}

* The vaccines are as per sequence given in the time schedule under immunization programme

** Fully vaccinated refers to those who received BCG, measles and three dose each of DPT and polio vaccines (excluding polio 0) 
and polio vaccine indicate that there is a dropout, the difference being about eleven percent for both DPT and Polio vaccines. More-over, only threefourth of children aged 12-23 months have been vaccinated against measles (Table 7). As expected, the levels of coverage were much higher for children with a vaccination card than those without a card.

Vitamin A deficiency is one of the common nutritional deficiencies. The National Programme on Prevention of Blindness targets children under age five years for administration of oral doses of vitamin A, every six months, starting at age nine months. Over one-third of children aged 12-47 months among Gujjars received at least one dose of vitamin A (Table 8A).

Out of those who received a least one dose, over one-fourth received a dose within the past six months (Table 8B). This reflects that a large majority of children have not received vitamin A supplementation at all, and even fewer receive it regularly. More boys than girls (though the difference is small) and more children whose mothers completed at least high school received vitamin A supplementation. Maternal education thus, influences the use of preventive health service like immunization as also reported by Streatfield and his colleagues (Streatfield et al., 1990).

Child Morbidity and Treatment: Acute respiratory infections (ARI), primarily pneumonia, diarrhoea and low birth weight are the

Table 8A: Percent distribution of children aged 12-47 months, by whether they received at least one dose of vitamin A or not, by selected characteristics

\begin{tabular}{|c|c|c|c|c|}
\hline \multirow[t]{2}{*}{$\begin{array}{l}\text { Chara- } \\
\text { cteristics }\end{array}$} & \multirow[t]{2}{*}{$\begin{array}{l}\text { Number of } \\
\text { children }\end{array}$} & \multicolumn{2}{|c|}{$\begin{array}{l}\text { Whether } \\
\text { received at least } \\
\text { one dose of } \\
\text { vitamin A or not }\end{array}$} & \multirow[t]{2}{*}{$\begin{array}{c}\text { Total } \\
\text { percent }\end{array}$} \\
\hline & & Yes & No & \\
\hline Total Sample & 160 & 36.3 & 63.8 & 100.0 \\
\hline \multicolumn{5}{|c|}{ Age of Child (in months) } \\
\hline $12-23$ & 62 & 38.7 & 61.3 & 100.0 \\
\hline $24-47$ & 98 & 34.7 & 65.3 & 100.0 \\
\hline \multicolumn{5}{|l|}{ Gender of Child } \\
\hline Males & 101 & 36.6 & 63.4 & 100.0 \\
\hline Females & 59 & 35.6 & 64.4 & 100.0 \\
\hline \multicolumn{5}{|l|}{ Mother's Education } \\
\hline Illiterate & 41 & 26.8 & 73.2 & 100.0 \\
\hline$<$ Middle school & ol 51 & 31.4 & 68.6 & 100.0 \\
\hline Middle school & 38 & 39.5 & 60.5 & 100.0 \\
\hline $\begin{array}{l}\text { High school and } \\
\text { above }\end{array}$ & d 30 & 53.3 & 46.7 & 100.0 \\
\hline
\end{tabular}

major causes of death among infants and children in India (NIHFW report, 1999-2000). Among Gujjars one in every fifteen children under four years of age suffered from the acute respiratory infection (cough accompanied by short and fast breathing) at some time during the two weeks before the study (Table 9). The most vulnerable for ARI were children between 0-5 months of age. Negligible differences are observed according to the gender of the child. The prevalence of ARI varies rather irregularly by mother's educational level.

Fever is another major cause of child morbidity which accompanies various illnesses importantly with malaria. The incidence of fever, during two weeks was lower than diarrhoea. About twelve percent of the children suffered from fever (Table 9). Children aged 6-23 months were somewhat more prone to fever. Fever is also more common in females than males. No consistent relationship is observed between the prevalence of fever and the education of the mother.

Diarrhoea is the most common of the three conditions examined during the study. One-fifth of the children under four years of age had diarrhoea during two weeks prior to study (Table 9). The incidence of diarrhoea declines with increasing age. Children aged 36-47 months are least susceptible to diarrhoea. Diarrhoea is more prevalent among males than females and higher among children of illiterate women.

Table 8B: Percent distribution of children aged 12-47 months, by whether received at least one dose of vitamin A within six months prior to study, by selected characteristics

\begin{tabular}{|c|c|c|c|c|}
\hline \multirow[t]{2}{*}{$\begin{array}{l}\text { Chara- } \\
\text { cteristics }\end{array}$} & \multirow[t]{2}{*}{$\begin{array}{l}\text { Number } \\
\text { of } \\
\text { children }\end{array}$} & \multicolumn{2}{|c|}{$\begin{array}{l}\text { Whether } \\
\text { received at least } \\
\text { one dose of } \\
\text { vitamin A or not }\end{array}$} & \multirow[t]{2}{*}{$\begin{array}{c}\text { Total } \\
\text { percent }\end{array}$} \\
\hline & & Yes & No & \\
\hline Total & 58 & 27.6 & 72.4 & 100.0 \\
\hline \multicolumn{5}{|c|}{ Age of Child (in months) } \\
\hline $12-23$ & 21 & 47.6 & 52.4 & 100.0 \\
\hline $24-47$ & 37 & 16.2 & 83.8 & 100.0 \\
\hline \multicolumn{5}{|l|}{ Gender of Child } \\
\hline Males & 37 & 29.7 & 70.3 & 100.0 \\
\hline Females & 21 & 23.8 & 76.2 & 100.0 \\
\hline \multicolumn{5}{|c|}{ Mother's Education } \\
\hline Illiterate & 11 & 18.2 & 81.8 & 100.0 \\
\hline$<$ Middle school & 16 & 18.8 & 81.2 & 100.0 \\
\hline Middle school & 15 & 20.0 & 80.0 & 100.0 \\
\hline $\begin{array}{l}\text { High school and } \\
\text { above }\end{array}$ & 16 & 50.0 & 50.0 & 100.0 \\
\hline
\end{tabular}


A look at the treatment pattern reflects that majority of children who suffered from Acute Respiratory Infection were taken to a health facility (e.g. hospital) or provider (doctor) for treatment (Table 10). About one-eighth of the children with ARI did not receive any treatment. Suffering children were most often treated with Pills and cough syrup. More than four-fifth of the children with fever were taken to a health facility or provider for treatment (Table 11). Majority of children were treated with Pills and injections. Anti-malarial medication was given to less than ten percent of the children.

Deaths from acute diarrhoea are most often caused by dehydration due to loss of electrolytes and water (Black, 1984). Such a condition is

\begin{tabular}{|c|c|c|c|c|}
\hline \multirow{2}{*}{$\begin{array}{l}\text { Character- } \\
\text { Istics }\end{array}$} & \multirow{2}{*}{$\begin{array}{c}\text { Number } \\
\text { of } \\
\text { children }\end{array}$} & \multicolumn{3}{|c|}{ Children suffering from } \\
\hline & & Cough & Fever & arrhoea \\
\hline Total & 221 & 6.8 & 11.8 & 19.9 \\
\hline \multicolumn{5}{|c|}{ Age of Child (in months) } \\
\hline $0-5$ & 21 & 19.0 & 4.8 & 28.6 \\
\hline $6-11$ & 40 & 10.0 & 15.0 & 27.5 \\
\hline $12-23$ & 62 & 8.1 & 14.5 & 22.6 \\
\hline $24-35$ & 54 & 1.9 & 9.3 & 18.5 \\
\hline $36-47$ & 44 & 2.3 & 11.4 & 6.8 \\
\hline \multicolumn{5}{|l|}{ Gender of Child } \\
\hline Males & 134 & 6.7 & 10.4 & 20.9 \\
\hline Females & 87 & 6.9 & 13.8 & 18.4 \\
\hline \multicolumn{5}{|c|}{ Education of Mother } \\
\hline Illiterate & 55 & 5.5 & 5.5 & 32.7 \\
\hline$<$ Middle & 62 & 3.2 & 14.5 & 19.4 \\
\hline Middle school & 55 & 10.9 & 9.1 & 18.2 \\
\hline $\begin{array}{l}\text { High school and } \\
\text { above }\end{array}$ & 49 & 8.2 & 18.4 & 8.2 \\
\hline
\end{tabular}

Table 10: Percent distribution of children under four years of age, having cough accompanied by short and rapid breathing in the past two weeks, by treatment

\begin{tabular}{lcc}
\hline Characteristics & \multicolumn{2}{c}{ Total } \\
\cline { 2 - 3 } & Number & Percent \\
\hline Treatment & 2 & \\
$\quad$ Not treated & 13.3 \\
$\quad$ Taken to hospital or doctor13 & 86.7 \\
\hline Total & 15 & 100.0 \\
\hline If Treated & & \\
Injection & 4 & 30.8 \\
Pills & 9 & 69.2 \\
Syrup & 11 & 84.6 \\
Home remedy & - & - \\
\hline
\end{tabular}

preventable. In India, the government has launched the Oral Rehydration Therapy Programme as one of its priority activities for child survival. Majority of children who had diarrhoea during two weeks before the study were taken to a health facility or provider for treatment (Table 12).

Treatment at a health facility or by a health provider was more common for children under two years of age and for male children. The differentials in the likelihood of taking treatment or medical advice for diarrhoea with respect to mother's education do not reflect a consistent pattern. Less than one-third of the children who suffered from diarrhoea during two weeks preceding the study were treated with ORS packets (Table 13) indicating that in spite of fact that government provide ORS packets free of cost and repeatedly propagate the use of ORS (now WHO recommended ORS) for children suffering from diarrhoea, people still are unaware or are not conscious of its use.

However, the likelihood of using ORS increases with increase in the level of education of the mother. Three-fifth received recommended home solution (RHS). While, only 31 percent of children received increased fluids such as plain water, juice, barley water, etc when suffering from diarrhoea. Although use of other anti-diarrhoeal drugs is not generally recommended for the treatment of childhood diarrhoea yet these may be useful in reducing duration and severity of diarrhoea, if needed (Table 13). One-third of the children were treated with pills or syrup and ten percent received an injection indicating that possibly mothers consulted such private health providers who are quacks having poor know-

Table 11: Percent distribution of children under four years of age having fever in the past two weeks, by treatment

\begin{tabular}{lcc}
\hline Characteristics & \multicolumn{2}{c}{ Total } \\
\cline { 2 - 3 } & Number & Percent \\
\hline Treatment & 4 & \\
$\quad$ Not treated & & 15.4 \\
Taken to hospital or doctor22 & 84.6 \\
\hline Total & 26 & 100.0 \\
\hline If Treated & & \\
Injection & 15 & 68.2 \\
Pills or syrup & 19 & 86.4 \\
Anti-malarial & 2 & 9.1 \\
Home remedy & - & - \\
\hline
\end{tabular}


Table 12: Percent distribution of children under four years of age, having diarrhoea in the past two weeks, by whether treated or not, according to selected characteristics

\begin{tabular}{|c|c|c|c|c|}
\hline \multirow[b]{2}{*}{$\begin{array}{l}\text { Chara- } \\
\text { cteristics }\end{array}$} & \multirow[b]{2}{*}{$\begin{array}{l}\text { Not } \\
\text { treated }\end{array}$} & \multicolumn{3}{|c|}{ If treated for diarrhoea, then } \\
\hline & & $\begin{array}{l}\text { Taken to } \\
\text { hospital } \\
\text { or doctor }\end{array}$ & $\begin{array}{l}\text { Home } \\
\text { remedy }\end{array}$ & $\begin{array}{l}\text { Number of } \\
\text { children } \\
\text { having } \\
\text { diarr- } \\
\text { hoea }\end{array}$ \\
\hline \multicolumn{5}{|c|}{ Age of Child (in months) } \\
\hline $0-11$ & - & 82.4 & 17.6 & 17 \\
\hline $12-23$ & 7.1 & 78.6 & 14.3 & 14 \\
\hline $24-47$ & 30.8 & 53.8 & 15.4 & 13 \\
\hline \multicolumn{5}{|l|}{ Gender of Child } \\
\hline Males & 7.1 & 82.1 & 10.7 & 28 \\
\hline Females & 18.8 & 56.3 & 25.0 & 16 \\
\hline \multicolumn{5}{|c|}{ Education of Mother } \\
\hline Illiterate & 16.7 & 61.1 & 22.2 & 18 \\
\hline$<$ Middle school & 18.3 & 75.0 & 16.7 & 12 \\
\hline Middle school & 10.0 & 80.0 & 10.0 & 10 \\
\hline \multicolumn{4}{|l|}{ High school and } & 4 \\
\hline Total Percent & 11.4 & 72.7 & 15.9 & - \\
\hline Number & 5 & 32 & 7 & 44 \\
\hline
\end{tabular}

ledge about proper treatment of diarrhoea. Less than one-fifth were treated at home.

It is inappropriate to reduce the frequency of breastfeeding or total intake of mother's milk or other fluids when a child is suffering with diarrhoea. In majority of children the amount of other fluids given was maintained at the same level (Table 14). About one in every six children with diarrhoea was given less fluid than they received before the diarrhoea began. The percentage of children who were given less fluids was less among those who were under one year than those who were older. For majority of children the frequency of breastfeeding was also unchanged. The frequency increased during the diarrhoea in over one-sixth of children and decreased in less than ten percent of children. The frequency of breastfeeding was the same for a larger proportion of children under one year than those who were older.

Breastfeeding Practices and Supplementation: Breastfeeding practices have significant effects on child survival and health as well as maternal fertility. It improves the nutritional status of children and reduces morbidity and mortality. The duration and frequency of breast-feeding have effects on the duration of post-partum amenorrhoea, births intervals and hence fertility. The timing and type of supplementary foods introduced in the infant's diet also affects the child's nutritional status. Reproductive and Child Health programme, Government of India, recommends that infants should be exclusively breastfed up to six months of age and continued breastfeeding with appropriate complementary feeding for up to two years of age and beyond. Initiation of breastfeeding immediately after childbirth is important as it benefits both the mother and the infant. The first breast secretion, called colostrum, provides natural immunity to

Table 13: Percent distribution of children under four years of age, having diarrhoea in the past two weeks, and who were treated, by treatment obtained, according to selected characteristics

\begin{tabular}{|c|c|c|c|c|c|c|c|}
\hline \multirow[t]{2}{*}{ Characteristics } & \multicolumn{5}{|c|}{ Treatment received } & \multirow{2}{*}{$\begin{array}{c}\text { Home } \\
\text { remedy }\end{array}$} & \multirow{2}{*}{$\begin{array}{l}\text { Number of } \\
\text { children who } \\
\text { were treated }\end{array}$} \\
\hline & $O R S$ & RHS & $\begin{array}{l}\text { Increased } \\
\text { fluids }\end{array}$ & $\begin{array}{l}\text { Pills/ } \\
\text { syrup }\end{array}$ & Injection & & \\
\hline \multicolumn{8}{|l|}{ Age of Child (in months) } \\
\hline $0-11$ & 23.5 & 58.8 & 23.5 & 17.6 & 11.8 & 17.6 & 17 \\
\hline $12-23$ & 38.5 & 61.5 & 53.8 & 61.5 & 7.7 & 15.4 & 13 \\
\hline $24-47$ & 33.3 & 66.7 & 11.1 & 22.2 & 11.1 & 22.2 & 9 \\
\hline \multicolumn{8}{|l|}{ Gender of Child } \\
\hline Males & 30.8 & 69.2 & 26.9 & 34.6 & 11.5 & 11.5 & 26 \\
\hline Females & 30.8 & 46.2 & 38.5 & 30.8 & 7.7 & 30.8 & 13 \\
\hline \multicolumn{8}{|l|}{ Education of Mother } \\
\hline Illiterate & 26.7 & 66.7 & 26.7 & 40.0 & - & 26.7 & 15 \\
\hline$<$ Middle school & 27.3 & 72.7 & 27.3 & 36.4 & 9.1 & 18.2 & 11 \\
\hline Middle school & 22.2 & 55.6 & 33.3 & 33.3 & 11.1 & 11.1 & 9 \\
\hline High school and above & 75.0 & 25.0 & 50.0 & - & 50.0 & - & 4 \\
\hline \multirow[b]{2}{*}{ Number } & 30.8 & 61.5 & 30.8 & 33.3 & 10.3 & 17.9 & - \\
\hline & 12 & 24 & 12 & 13 & 4 & 7 & 39 \\
\hline
\end{tabular}

Note: ORS,RHS and increased fluids comes under oral re-hydration therapy (ORT) 
Table 14: Percent distribution of children under four years of age, having diarrhoea in the past two weeks, by feeding practices during diarrhoea and age

\begin{tabular}{lcc}
\hline $\begin{array}{l}\text { Feeding practices } \\
\text { during diarrhoea }\end{array}$ & \multicolumn{2}{c}{$\begin{array}{c}\text { Age of child } \\
\text { (in months) }\end{array}$} \\
\cline { 2 - 3 } & $0-11$ & $0-47^{*}$ \\
\hline Amount of Fluids Given & & \\
$\quad$ Same as usual & 64.7 & 56.8 \\
More & 23.5 & 27.3 \\
$\quad$ Less & 11.8 & 15.9 \\
\hline Total percent & 100.0 & 100.0 \\
\hline Number of children with diarrhoea & 17 & 44 \\
Frequency of Breastfeeding & 76.5 & 73.9 \\
$\quad$ Same as usual & 17.6 & 17.4 \\
Increased & 5.9 & 8.7 \\
$\quad$ Decreased & 100.0 & 100.0 \\
\hline Total percent & 17 & 23 \\
\hline Number of children who are & & \\
$\quad$ still breastfed & & \\
\hline
\end{tabular}

*Includes children who are aged 0-11 months

the child, and thus should be given to the child instead of discarding it (Reddy, 1995; Park, 1997). In the present study the number of children who received breast milk and plain water are included in the category of full breast-feeding i.e., exclusive breastfeeding. Although breastfeeding is universal among Gujjar women, only eight percent of the children (born during last four years) begin breastfeeding within one hour of birth (Table 15).

Slightly more than half of the children begin breastfeeding within 24 hours of birth. There is negligible difference in the timing of initiation of breastfeeding by the gender of the child. The postponement of initiation of breastfeeding is more common among illiterate women than literate. Children whose delivery was assisted by a health professional and children born in public or private medical institutions begin breastfeeding earlier than other children reflecting that circumstances surrounding delivery also have an important effect on early initiation of breastfeeding (Table 15).

Three-fifth of the children aged 0-5 months are fully breastfed while remaining are partially breastfed (i.e., received supplements such as other milk like cow's milk, other liquid, or solid or mushy food). The proportion of children who are fully breastfed decreases rapidly with age as children are gradually weaned from the breast (Table 16). Majority of children among Gujjars have stopped breastfeeding by 24-29 months of age. About two-fifth of children received breast milk along with supplements such as other milk such as cow's milk, other liquid or solid or mushy food before six months of age, as against recommended by Ministry of Health and Family Welfare (1997).

The median duration of total breastfeeding among Gujjars is 18 months (average: 17.92 months). The median duration of full breastfeeding is 3 months (mean: 3.10) while that of partial breastfeeding is 14 months (mean: 14.65) reflecting that supplementation begins relatively early. Durations of breastfeeding are associated with factors, like survival of baby, age of the mother, parity, education of the mother, gender of the child (Jain and Bongaarts, 1981; Smith, 1985; Ahmad and Alam, 1996).

\section{CONCLUSIONS}

From the foregoing discussion, it may be concluded that majority of women received antenatal check-ups, though institutional deliveries are less common. Perhaps, conservative thoughts still prevent mothers from seeking trained health professional's help and compel them for traditional methods during delivery; particularly when there are no complications. It also reflects that health services

Table 15: Percent distribution of children under four years of age, who were ever-breastfed, by initiation of breastfeeding and selected characteristics

\begin{tabular}{|c|c|c|c|}
\hline \multirow{2}{*}{$\begin{array}{l}\text { Charac- } \\
\text { teristics }\end{array}$} & \multicolumn{2}{|c|}{ Started breastfeeding } & \multirow[b]{2}{*}{$\begin{array}{l}\text { Number } \\
\text { of } \\
\text { children }\end{array}$} \\
\hline & $\begin{array}{l}\text { Within } \\
1 \text { hour of } \\
\text { birth }\end{array}$ & $\begin{array}{l}\text { Within } \\
24 \text { hours } \\
\text { of birth* }\end{array}$ & \\
\hline \multicolumn{4}{|l|}{ Gender of Child } \\
\hline Males & 8.2 & 52.2 & 134 \\
\hline Females & 8.0 & 51.7 & 87 \\
\hline \multicolumn{4}{|l|}{ Education of Mother } \\
\hline Illiterate & 5.5 & 32.7 & 55 \\
\hline Literate & 9.0 & 58.4 & 166 \\
\hline \multicolumn{4}{|l|}{ Place of Delivery } \\
\hline Public health facility & 12.5 & 62.5 & 8 \\
\hline Private health facility & 12.3 & 65.8 & 73 \\
\hline At home & 5.7 & 44.3 & 140 \\
\hline \multicolumn{4}{|l|}{ Assistance at Delivery } \\
\hline Health professional & 10.2 & 61.4 & 127 \\
\hline Traditional birth attendant & t 5.3 & 39.4 & 94 \\
\hline Total & 8.1 & 52.0 & 221 \\
\hline
\end{tabular}

* Includes children who started breastfeeding within one hour of birth 
Table 16: Percent distribution of children under four years of age, by breastfeeding status and age of child

\begin{tabular}{|c|c|c|c|c|c|c|c|c|}
\hline \multirow{2}{*}{$\begin{array}{l}\text { Age } \\
\text { (in months) }\end{array}$} & \multirow{2}{*}{$\begin{array}{l}\text { Not breast } \\
\text { feeding }\end{array}$} & \multirow{2}{*}{$\begin{array}{l}\text { Breast- } \\
\text { feeding }\end{array}$} & \multicolumn{2}{|c|}{ Total } & \multicolumn{2}{|c|}{ If breastfeeding } & \multicolumn{2}{|c|}{ Total } \\
\hline & & & Percent & Number & $\begin{array}{c}\text { Full } \\
\text { breast } \\
\text { feeding* }\end{array}$ & $\begin{array}{c}\text { Partial } \\
\text { breast } \\
\text { feeding** }\end{array}$ & Percent & Number \\
\hline $0-5$ & - & 100.0 & 100.0 & 21 & 61.9 & 38.1 & 100.0 & 21 \\
\hline $6-11$ & 5.0 & 95.0 & 100.0 & 40 & 28.9 & 71.1 & 100.0 & 38 \\
\hline $12-17$ & 25.0 & 75.0 & 100.0 & 12 & 11.1 & 88.9 & 100.0 & 9 \\
\hline $18-23$ & 58.0 & 42.0 & 100.0 & 50 & 4.8 & 95.2 & 100.0 & 21 \\
\hline 24-29 & 80.0 & 20.0 & 100.0 & 5 & - & 100.0 & 100.0 & 1 \\
\hline $30-35$ & 85.7 & 14.3 & 100.0 & 49 & - & 100.0 & 100.0 & 7 \\
\hline $36-41$ & 100.0 & - & 100.0 & 4 & - & - & - & - \\
\hline $42-47$ & 100.0 & - & 100.0 & 40 & - & - & - & - \\
\hline Total & 124 & 97 & - & 221 & 26 & 71 & - & 97 \\
\hline
\end{tabular}

* Full breastfeeding refers to exclusive breastfeeding plus breastfeeding along with plain water

** Partial breastfeeding refers to breastfeeding along with supplements like other milk such as cow's milk, other liquid or solid or mushy food.

in Delhi are availed by many more women during pregnancy than during delivery and points to the important role played by traditional birth attendants. Besides, the recommended need of a minimum of three antenatal check-ups, the coverage of other two interventions, namely two tetanus toxoid injections and full course of iron and folic acid supplementation is incomplete among Gujjar women. Higher educated mothers have more likelihood for antenatal care and institutional deliveries.

Though breastfeeding is universal among Gujjars; supplementation begins relatively early. Immunization coverage is far from complete. Proportion of fully vaccinated children is low, besides dropout in DPT and polio vaccination series is also a problem. Vitamin A supplementation below 5 years of age is not only incomplete but also irregular. Diarrhoea is the most frequent cause of child morbidity among Gujjars. Treatment of the three childhood ailments under study is fairly high among Gujjars, possibly because of availability and increased utilization of health facilities.

On the basis of the results of the present study it may be suggested that there is a need to make Gujjar mothers aware of the benefits and necessity of antenatal check-ups, iron and folic acid supplements, professional medical care during pregnancy and delivery, full immuni-zation of children, regular supple-mentation of vitamin A and use of ORS solution (WHO recommended) for diarrhoea, by giving proper and adequate information regarding these interventions.

\section{ACKNOWLEDGEMENT}

We are grateful to the families who form the basis of present study without whose co-operation and kind help, this work would not have been so smoothly possible.

\section{REFERENCES}

Ahmad, S. and Alam, Md. S.: Determinants of breastfeeding in an urban area of bangladesh. Journal of Family Welfare, 42(1): 1-6 (1996).

Babu, K.S.: The Influence of traditional occupation on breastfeeding pattern. Man in India, 76(3): 267-272 (1996).

Black, R.E.: Diarrhoeal diseases and child mortality, In: Child Survival Strategies for Research. W. Henry Mosley and Lincoln C. Chen (Eds.). Population and Development Review, Supplement to Volume 10 (1984).

Dabral, S. and Malik, S.L.: Demography study of Gujjars of Delhi: I. Population structure and socio-cultural profile. Journal of Human Ecology, 16(1): 17-24 (2004a)

Guha, A.: Health care among two rural population of Assam: A Comparative study, pp. 207-248. In: Cultural and Environmental Dimensions on Health, Buddhadeb Chaudhuri (Ed.). Inter-Indian Publications. New Delhi (1990).

Jain, A.K. and Bongaarts, J.: Breastfeeding: Patterns, correlates and fertility effects. Studies in Family Planning, 12(3): 79-99 (1981).

Joesoef, R.M., Utomo, B., and Lewis, G.L: Breastfeeding practices in metropolitan Indonesia: Policy considerations. Journal of Tropical Paediatrics, 34: 1014 (1988).

Kar, R.K.: Health behaviour among the Tribes of North-East India: A profile. Journal of India Anthropological Society, 28: 157-164 (1993).

MacDonald, Paul C. and Pritchard, Jack A.: Williams Obstetrics. $16^{\text {th }}$ Ed. Appleton-Century-Crofts, New York 
(1980).

Manocha, S., Manocha, A. and Vir, D.: Cultural beliefs and practices affecting the utilization of health services during Pregnancy. Journal of Indian Anthropological Society, 27(2): 181-185 (1992).

Ministry of Health and Family Welfare-MHFW: Reproductive and Child Health Programme: Schemes for Implementation. Department of Family Welfare, MHFW, New Delhi (1997).

Mohiuddin, A.M.: Breastfeeding in Bangladesh. Journal of Bio-social Science, 18(4): 425-434 (1986).

Montagu, A.: Human Heredity. The New American Library of World Literature, New York (1963).

Mott, S.H.: A Note on the determinants of breastfeeding durations in an African country. Social Biology, 31: 279-288 (1984)

NewCombe, H.B.: Screening for effects of maternal age and birth order in a register of handicapped children. Annals of Human Genetics, 27: 367-382 (1964).

NIHFW Report (1999-2000). National Institute of Health and Family Welfare. Department of Family Welfare, India (2000).

Otta, B.M.: The impact of maternal education on the health of the child. Journal of Family Welfare, 38(4): 19-24 (1992).

Park, K.: Park's Textbook of Preventive and Social Medicine. $15^{\text {th }} \mathrm{Ed}$. M/s Banarsidas Bhanot, Jabalpur (1997).

Ramachandran, Prema: Need of organization of antenatal and intrapartum care in India. Demography India, 21(2): 179-193 (1992)

Reddy, S.: Breastfeeding-practices, problems and prospects.
Journal of Family Welfare, 41(4): 43-51(1995).

RGI: Survey of Causes of Death (Rural) India. Annual Report. Office of Registrar General of India, New Delhi (1997).

Singh, K.K., Suchindran, C.M. and Singh, R.S.: Smoothed breastfeeding durations and waiting time to conception. Social Biology, 41: 229-239 (1994).

Singh, Kaushalendra K., Suchindran, Chirayath M. and Singh, Kiran: Breastfeeding and postpartum amenorrhoea: An Indian experience. Demography India, 28(1): 1-12 (1999).

Singh, V.K. and Negi, K.S.: An investigation into relationship between breastfeeding and amenorrhoea, In: Principles and Practice of Statistics in Medicine, R.N. Srivastava, B.L.Verma and G.D.Shukla (Eds.). H.P.House, New Delhi (1985).

Smith, D.P.: Breastfeeding, contraception and birth interval in developing countries. Studies in Family Planning, 16(3): 154-163 (1985).

Srinivasan, K., Pathak, K.B. and Pandey, A.: Determinants of breast feeding and post-partum amenorrhoea in Orissa. Journal of Biosocial Science, 21(3): 365-371 (1989).

Streatfield, Kim, Singarimbun, Masri and Diamond, Ian: Maternal education and child immunization. Demography, 27(3): 447-455 (1990).

UNICEF: Children and Women in India (A Situation Analysis 1990). UNICEF, Indian Office, Planning Section, New Delhi (1990).

Wyon, John B. and Gordon, John B.: The Khanna Study: Population Problems in the Rural Punjab. Cambridge University Press, Cambridge (1971). 